\title{
Patient Satisfaction With Inhaled Medication for Asthma
}

\author{
Ashutosh N Aggarwal MD, Raman Kumari MD, and Sandeep Grover MD
}

\begin{abstract}
BACKGROUND: We sought to compare treatment satisfaction with inhaled medications among asthmatics using a metered-dose inhaler (MDI) or a dry-powder inhaler (DPI), and to correlate satisfaction with treatment adherence, pulmonary function, and airway inflammation. METHODS: Spirometry, fraction of expired nitric oxide $\left(F_{\mathrm{ENO}}\right)$, and asthma control were assessed in 200 adult subjects with asthma (69 men, 131 women) using MDI or DPI. Treatment satisfaction with inhaled therapy was assessed with the Treatment Satisfaction Questionnaire for Medication (TSQM) in 4 domains: Effectiveness, Side Effects, Convenience, and Global Satisfaction. The Medication Adherence Questionnaire (MAQ) was used to evaluate adherence to treatment. RESULTS: There were 115 and 85 subjects with asthma, using MDI and DPI, respectively. More MDI users $(40.9 \%)$ had wellcontrolled asthma as compared to DPI users $(\mathbf{1 7 . 6 \%})$. MDI users had greater treatment adherence and better TSQM domain scores for Effectiveness, Convenience, and Global Satisfaction than did DPI users. Multivariate linear regression analysis revealed no significant association between MDI/DPI use and TSQM domain scores. TSQM Convenience and Global Satisfaction domain scores were significantly correlated with MAQ scores (Spearman's coefficients 0.211 and $0.218, P=.003$ and $P=.002$, respectively). There was no significant correlation between any TSQM domain score and pulmonary function or $\mathbf{F}_{\mathrm{ENO}}$ concentration. CONCLUSIONS: MDIs were associated with better disease control and treatment adherence among subjects with asthma. Both MDI and DPI are likely to provide equivalent treatment satisfaction. Key words: asthma; inhaler devices; patient satisfaction; treatment adherence. [Respir Care 2018;63(7):859-864. (C) 2018 Daedalus Enterprises]
\end{abstract}

\section{Introduction}

Asthma medications are preferably delivered through the inhaled route. However, inhalers were considered taboo, socially unacceptable, or habit-forming by some

Drs Aggarwal MD and Kumari are affiliated with the Department of Pulmonary Medicine, Postgraduate Institute of Medical Education and Research, Chandigarh, India. Dr Grover is affiliated with the Department of Psychiatry, Postgraduate Institute of Medical Education and Research, Chandigarh, India.

Dr Aggarwal presented a version of this article at the Annual Conference of the American College of Chest Physicians, held October 22-26, 2016, in Los Angeles, California.

The authors have disclosed no conflicts of interest.

Correspondence: Ashutosh N Aggarwal MD, Professor of Pulmonary Medicine, Postgraduate Institute of Medical Education and Research, Chandigarh, India. E-mail: aggarwal.ashutosh@outlook.com.

DOI: $10.4187 /$ respcare. 05544
Indian patients, especially in rural areas. The situation has improved due to improved availability, reduced device cost, and emphasis on health education. A variety of metered-dose inhalers (MDIs) and dry-powder inhalers (DPIs) are manufactured and marketed by several Indian pharmaceutical companies, and a few international devices are also available. In general, clinical outcomes with either MDI or DPI appear similar if the dosing and technique of inhalation are appropriate. ${ }^{1}$ As clinicians, we often focus on the level of asthma control as the hard end point to assess treatment efficacy, and patient-related factors such as treatment preferences, satisfaction, and adherence, among others, are not assessed routinely.

Patients may not be fully satisfied with their asthma medications for a variety of reasons, including cost, complexity of the device, adverse effects, perceived stigma, and suboptimal improvement in health status. This in turn may negatively influence adherence to therapy and may result in a lower likelihood of successfully achieving asthma treatment goals. ${ }^{2,3}$ A small Indian study noted that subjects newly trained to use a particular Indian DPI device were 
largely satisfied with its use. ${ }^{4}$ However, to our knowledge, no previous Indian study has explored various issues related to patient satisfaction among subjects with asthma who use long-term inhaled therapy. We therefore assessed treatment satisfaction with inhaled medications among stable asthmatics using either MDIs or DPIs, and we correlated satisfaction with the type of inhaler device, treatment adherence, lung function, and airway inflammation.

\section{Methods}

We enrolled 200 consecutive adult subjects with asthma (69 men, 131 women; age $\geq 18$ y) who attended the chest clinic of our institute from January 2015 to December 2015. Subjects were required to have used an MDI or a DPI manufactured by an Indian company for at least the past year. The diagnosis of asthma was based on a combination of typical symptoms (eg, wheezing, coughing, chest tightness, or shortness of breath) and documentation of air-flow limitation on spirometry. All subjects spoke and understood Hindi well. Proper inhaler technique had been demonstrated and verified on at least one previous out-patient visit for all subjects. Patients who experienced disease exacerbation requiring treatment augmentation, systemic corticosteroid therapy, or an emergency room visit in the last 4 weeks were excluded. Patients with asthma with coexisting medical conditions that could potentially worsen quality of life or impair the level of activity were also excluded, as were pregnant women. Informed consent was obtained from all subjects included in the study, and the study protocol was approved by our institutional ethics committee.

Baseline demographic and clinical details were gathered from all subjects. Asthma symptom control was categorized as good, partial, or poor according to Global Initiative for Asthma (GINA) guidelines. ${ }^{5}$ Spirometry was performed by trained technicians using a dry rolling seal spirometer (Spiro RS232; PK Morgan, United Kingdom) per standard guidelines. ${ }^{6}$ Subjects' observed FVC, FEV ${ }_{1}$, and $\mathrm{FEV}_{1} / \mathrm{FVC}$ ratio were compared to predicted norms previously derived for north Indians at our institute. ${ }^{7}$ An $\mathrm{FEV}_{1} / \mathrm{FVC}$ ratio below the predicted lower limit of normal for an individual was considered to represent an obstructive defect. Fraction of expired nitric oxide $\left(\mathrm{F}_{\mathrm{ENO}}\right)$ was measured orally through a portable online analyzer (NObreath, Bedfont Scientific, United Kingdom). The average of 3 reproducible measurements was expressed in $\mathrm{ppb}$, with higher readings indicating more severe airway inflammation. ${ }^{8}$ Satisfaction with inhaled therapy was assessed using the Hindi adaptation of the Treatment Satisfaction Questionnaire for Medication (TSQM), version 1.4. ${ }^{9}$ This 14-item questionnaire provides transformed scores ranging from 0-100 in 4 domains (ie, Effectiveness, Side Effects, Convenience, and Global Satisfaction), with higher scores suggestive of greater satisfaction. Subjects with

\section{QUICK LOOK}

\section{Current knowledge}

Patients may not be fully satisfied with their asthma medications due to several reasons. The device used for inhaled therapy may influence patient satisfaction and adherence.

\section{What this paper contributes to our knowledge}

In a real-life clinical scenario, the use of metered-dose inhalers was associated with better disease control and treatment adherence compared to dry-powder inhalers. Both devices, however, seemed to provide equivalent treatment satisfaction. Treatment satisfaction with inhaled therapy correlated poorly with pulmonary function and airway inflammation.

asthma on inhaled therapy had participated in the original validation process of the TSQM, and the instrument has been used on patients taking inhaled medications for other respiratory disorders. ${ }^{10,11}$ Adherence to inhaled therapy was assessed with the Medication Adherence Questionnaire (MAQ), translated into the Hindi language. ${ }^{12}$ The MAQ has 4 Yes/No questions that address ways in which patients failed to take their prescribed medications over the last 3 months. ${ }^{12}$ Subjects with MAQ scores $0-1,2-3$, and 4 were considered to have low, medium, and high adherence to inhaled therapy, respectively.

All scores were summarized as medians and corresponding interquartile ranges (IQR). Group comparisons were made with nonparametric statistical tests (Mann-Whitney $U$ test for scalar variables and Fisher exact test for categorical variables). Correlations between variables of interest were evaluated through Spearman's coefficient. Multiple linear regression analysis was performed to identify variables that significantly influenced TSQM domain scores. Statistical significance was tested at $P<.05$. The statistical software SPSS (version 21; IBM, Armonk, New York) was used for analysis.

\section{Results}

The study population had $69(34.5 \%)$ men and 131 $(65.5 \%)$ women who had asthma symptoms for a median (IQR) duration of 8 (4-15) y (Table 1). Subjects were using inhaled drugs for a median (IQR) duration of 3 (18) y, either as MDI (114 [57.5\%] subjects) or as singlecapsule DPI (85 [42.5\%] subjects). Only $62(31.0 \%)$ subjects had well-controlled asthma. Nearly half of all subjects (98 [49.0\%] subjects) showed an obstructive defect on spirometry, and $38(19.0 \%)$ subjects had $\mathrm{F}_{\mathrm{ENO}}$ levels $>25$ ppb (Table 1). Only $62(31.0 \%)$ subjects had well- 
Table 1. Demographic and Clinical Characteristics of the Study Population

\begin{tabular}{|c|c|}
\hline Characteristics & Value \\
\hline \multicolumn{2}{|l|}{ Gender, $n(\%)$} \\
\hline Men & $69(34.5)$ \\
\hline Women & $131(65.5)$ \\
\hline Age, y & $40(30-50)$ \\
\hline \multicolumn{2}{|l|}{ Residence, $n(\%)$} \\
\hline Rural & $108(54.0)$ \\
\hline Urban & $92(46.0)$ \\
\hline \multicolumn{2}{|l|}{ Education, $n(\%)$} \\
\hline Illiterate & $36(18.0)$ \\
\hline Primary & $40(20.0)$ \\
\hline Higher secondary & $80(40.0)$ \\
\hline Graduate or higher & $44(22.0)$ \\
\hline \multicolumn{2}{|l|}{ Tobacco smoking, $n(\%)$} \\
\hline Smoker & $4(2.0)$ \\
\hline Non-smoker & $196(98.0)$ \\
\hline Disease duration, y & $8(4-15)$ \\
\hline Duration of inhaled therapy, y & $3(1-8)$ \\
\hline \multicolumn{2}{|l|}{ Type of inhaled drugs, $n(\%)$} \\
\hline ICS alone & $5(2.5)$ \\
\hline SABA alone & $21(10.5)$ \\
\hline ICS + SABA combination & $13(6.5)$ \\
\hline ICS + LABA combination & $158(79.0)$ \\
\hline Others & $3(1.5)$ \\
\hline \multicolumn{2}{|l|}{ Inhaler device, $n(\%)$} \\
\hline Metered-dose inhaler & $115(57.5)$ \\
\hline Single-capsule dry-powder inhaler & $85(42.5)$ \\
\hline \multicolumn{2}{|l|}{ Asthma control, $n(\%)$} \\
\hline Well controlled & $62(31.0)$ \\
\hline Partly controlled & $74(37.0)$ \\
\hline Uncontrolled & $64(32.0)$ \\
\hline \multicolumn{2}{|l|}{ Spirometry result, $n(\%)$} \\
\hline No obstruction & $102(51.0)$ \\
\hline Mild obstruction & $49(24.5)$ \\
\hline Moderate obstruction & $37(18.5)$ \\
\hline Severe obstruction & $12(6.0)$ \\
\hline$\%$ of predicted $\mathrm{FEV}_{1}$ & $73(53-93)$ \\
\hline$\%$ of predicted FVC & $87(65-102)$ \\
\hline $\mathrm{FEV}_{1} / \mathrm{FVC}, \%$ & $65(57-74)$ \\
\hline Fractional exhaled nitric oxide, parts per million & $17(8-25)$ \\
\hline \multicolumn{2}{|c|}{$\begin{array}{l}=200 \text { subjects. Data are expressed as frequency (\%) or median (interquartile range) as } \\
\text { appropriate. } \\
\text { ICS }=\text { inhaled corticosteroid } \\
\text { SABA = short-acting } \beta \text { agonist } \\
\text { LABA }=\text { long-acting } \beta \text { agonist }\end{array}$} \\
\hline
\end{tabular}

controlled asthma symptoms, and only $43(21.5 \%)$ were fully adherent to inhaled therapy. More MDI users (47 [40.9\%] subjects) had well-controlled asthma compared to DPI users (15 [17.6\%] subjects) (Table 2). MDI users also had significantly better MAQ scores than DPI users (median [IQR] 2 [1-3] vs 1 [1-3], $P=.043$ ) (Table 2).

On administering the TSQM, 169 (84.5\%) subjects reported no adverse effects related to inhaled therapy. Scores for the other 3 domains (ie, Effectiveness, Convenience, and Global Satisfaction) were more variable and widely distributed, and in general were significantly higher for MDI users than for DPI users (Table 2). Women, subjects with well-controlled asthma symptoms, and those taking a combination of inhaled corticosteroids and long-acting $\beta$ agonists had higher TSQM Effectiveness and Global Satisfaction domain scores (Table 3). TSQM Convenience and Global Satisfaction domain scores were significantly correlated with MAQ scores (Table 4). There was no significant correlation between any TSQM domain score and pulmonary function or $\mathrm{F}_{\mathrm{ENO}}$ concentration (Table 4).

On multiple linear regression analysis, TSQM domain scores were not influenced by the type of inhaler device being used (Table 5). Asthma control significantly influenced Effectiveness and Global Satisfaction domain scores, and treatment adherence significantly influenced Convenience and Global Satisfaction domain scores (Table 5). However, the coefficient of determination $\left(\mathrm{R}^{2}\right)$ was numerically small for all models. We also modeled the linear regression after adjusting for a potential interaction between device type and control of asthma. The inclusion of this interaction term did not alter the results of the regression analysis substantially (Table 5).

\section{Discussion}

Most of the subjects in this study were using MDIs, while others were using single-capsule DPIs. Single-capsule devices commonly used in India are modifications of the now discontinued Spinhaler (Aventis Pharma, Surrey United Kingdom) and Rotahaler (GlaxoSmithKline, Middlesex, United Kingdom). Despite being relatively inefficient as compared to standard MDIs, several subjects preferred these DPIs as they require much less hand-mouth coordination during inhalation, and they are available in smaller dose units, which makes them more affordable for poorer patients who could not otherwise afford a 200-dose MDI.

As compared to DPI users, MDI users in this study had higher prevalence of well-controlled asthma, showed greater adherence to inhaled therapy, and reported better satisfaction with treatment on 3 of 4 TSQM domains. Patient satisfaction with their medications is now increasingly recognized as an important patient-reported outcome in clinical practice. ${ }^{13}$ Previous studies have mainly evaluated patient satisfaction under clinical trial conditions, with specific inhaled drugs and devices being used by carefully selected subjects. Patient satisfaction with inhaled therapy depends not only on the inhaler device, but also on the administered drugs. ${ }^{14,15}$ If the drugs are similar, different devices may still show different levels of satisfaction. ${ }^{16}$ Other studies have reported similar levels of satisfaction between MDIs, DPIs, and other new devices. ${ }^{17,18}$ DPIs are also available in both single-dose and multi-dose formats, 


\section{Patient Satisfaction With Inhalers}

Table 2. Comparison of MDI vs DPI for Inhaled Therapy for Asthma

\begin{tabular}{|c|c|c|c|c|}
\hline Characteristics & MDI & DPI & Total & $P$ \\
\hline \multicolumn{5}{|l|}{ Asthma control, $n(\%)$} \\
\hline Well controlled & $47(40.9)$ & $15(17.6)$ & $62(31.0)$ & \multirow[t]{3}{*}{.001} \\
\hline Partly controlled & $40(34.8)$ & $34(40.0)$ & $74(37.0)$ & \\
\hline Poorly controlled & $28(24.3)$ & $36(42.4)$ & $64(32.0)$ & \\
\hline \multicolumn{5}{|l|}{ Lung function } \\
\hline $\mathrm{F}_{\mathrm{ENO}} \leq 25 \mathrm{ppb}$ & $92(80.0)$ & $70(82.4)$ & $162(81.0)$ & \multirow[t]{2}{*}{.72} \\
\hline $\mathrm{F}_{\mathrm{ENO}}>25 \mathrm{ppb}$ & $23(20.0)$ & 15 (17.6) & $38(19.0)$ & \\
\hline Overall & $15(6-23)$ & $12(7-22)$ & $14(6-22)$ & .90 \\
\hline$\%$ Predicted $\mathrm{FEV}_{1}$ & $81.5(63.4-94.9)$ & $73.0(53.2-93.3)$ & $77.1(59.5-94.1)$ & .044 \\
\hline \multicolumn{5}{|l|}{ MAQ score } \\
\hline High adherence, 4 & $27(23.5)$ & $16(18.8)$ & $43(21.5)$ & \multirow[t]{3}{*}{.11} \\
\hline Medium adherence, $2-3$ & $46(40.0)$ & $25(29.4)$ & $71(35.5)$ & \\
\hline Low adherence, $0-1$ & $42(36.5)$ & $44(51.8)$ & $86(43.0)$ & \\
\hline Overall & $2(1-3)$ & $1(1-3)$ & $2(1-3)$ & .043 \\
\hline \multicolumn{5}{|l|}{ TSQM score } \\
\hline Effectiveness & $72.2(66.7-83.3)$ & $66.7(61.1-77.8)$ & $72.2(61.1-83.3)$ & .004 \\
\hline Side Effects & $100(100-100)$ & $100(100-100)$ & $100(100-100)$ & .91 \\
\hline Convenience & $72.2(66.7-83.3)$ & $66.7(55.6-77.8)$ & $72.2(61.1-77.8)$ & .02 \\
\hline Global Satisfaction & $71.4(64.3-78.6)$ & $71.4(57.1-78.6)$ & $71.4(60.7-78.6)$ & .035 \\
\hline $\begin{array}{l}\text { Data are expressed as } n(\%) \text { or medi } \\
\text { MDI = metered-dose inhaler } \\
\text { DPI = dry-powder inhaler } \\
\text { F }_{\text {ENO }} \text { - fraction of expired nitric oxi } \\
\text { ppb = parts per billion } \\
\text { MAQ = Medication Adherence Que } \\
\text { TSQM = Treatment Satisfaction Qu }\end{array}$ & e) as applicable. & & & \\
\hline
\end{tabular}

Table 3. Impact of Demographic and Clinical Characteristics on TSQM Domain Scores

\begin{tabular}{|c|c|c|c|c|}
\hline Characteristics & Effectiveness & Side Effects & Convenience & Global Satisfaction \\
\hline \multicolumn{5}{|l|}{ Gender } \\
\hline Men & $66.7(61.1-77.8)^{*}$ & $100(100-100)$ & $66.7(61.1-77.8)$ & $71.4(57.1-78.6)^{*}$ \\
\hline Women & $72.2(61.1-83.3)$ & $100(100-100)$ & $72.2(61.1-77.8)$ & $71.4(64.3-78.6)$ \\
\hline \multicolumn{5}{|l|}{ Residence } \\
\hline Rural & $72.2(61.1-83.3)$ & $100(100-100)$ & $66.7(61.1-77.8)$ & $71.4(57.1-78.6)$ \\
\hline Urban & $72.2(63.9-80.6)$ & $100(100-100)$ & $72.2(61.1-83.3)$ & $71.4(64.3-78.6)$ \\
\hline \multicolumn{5}{|l|}{ Symptom control } \\
\hline Well controlled & $77.8(72.2-83.3)^{*}$ & $100(100-100)$ & $77.8(66.7-83.3)^{*}$ & $78.6(71.4-92.9)^{*}$ \\
\hline Partly/poorly controlled & $66.7(61.1-77.8)$ & $100(100-100)$ & $66.7(61.1-77.8)$ & $71.4(57.1-78.6)$ \\
\hline \multicolumn{5}{|l|}{ Inhaled drugs } \\
\hline ICS + LABA combination & $72.2(66.7-83.3)^{*}$ & $100(100-100)$ & $72.2(61.1-77.8)$ & $71.4(64.3-78.6)^{*}$ \\
\hline Other drugs & $63.9(55.6-72.2)$ & $100(100-100)$ & $66.7(55.6-77.8)$ & $64.3(50.0-78.6)$ \\
\hline \multicolumn{5}{|c|}{$\begin{array}{l}{ }^{* P} P .05 . \text { Data are expressed as median (interquartile range). } \\
\text { TSQM }=\text { Treatment Satisfaction Questionnaire for Medication } \\
\text { ICS }=\text { inhaled corticosteroid } \\
\text { LABA }=\text { long-acting } \beta \text { agonist }\end{array}$} \\
\hline
\end{tabular}

and there is some suggestion that patients derive greater satisfaction with the latter. ${ }^{19,20}$ Unfortunately, no data are available to correlate the type of inhaler device with patient satisfaction in real-world scenarios. Our study is a preliminary attempt to fill this knowledge gap, and after adjusting for covariates in a multiple linear regression model, we found that the type of inhaler was not significantly associated with treatment satisfaction domain scores. This suggests that in real-life situations, both MDI and DPI may provide equal treatment satisfaction when other clinical variables are accounted for. We acknowledge, however, that our regression models explain only a small pro- 
Table 4. Correlations Between TSQM Domain Scores and Demographic and Clinical Characteristics

\begin{tabular}{|c|c|c|c|c|}
\hline Characteristics & Effectiveness & Side Effects & Convenience & Global Satisfaction \\
\hline Age & 0.11 & 0.18 & 0.01 & 0.11 \\
\hline Years of having asthma & -0.02 & 0.03 & 0.04 & 0.04 \\
\hline Years of inhaler use & -0.01 & -0.07 & 0.01 & 0.06 \\
\hline$\%$ Predicted $\mathrm{FEV}_{1}$ & -0.01 & -0.01 & $0.17 *$ & 0.02 \\
\hline $\mathrm{F}_{\mathrm{ENO}}$ & -0.13 & -0.08 & -0.09 & -0.09 \\
\hline MAQ score & 0.13 & 0.05 & $0.21 *$ & $0.22 *$ \\
\hline \multicolumn{5}{|c|}{$\begin{array}{l}\frac{* P<.05 .}{\mathrm{TSQM}=\text { Treatment Satisfaction Questionnaire for Medication }} \\
\mathrm{F}_{\mathrm{ENO}}=\text { fraction of expired nitric oxide } \\
\mathrm{MAQ}=\text { Medication Adherence Questionnaire }\end{array}$} \\
\hline
\end{tabular}

Table 5. Multiple Linear Regression Analysis to Assess Variables Significantly Influencing TSQM Domain Scores

\begin{tabular}{|c|c|c|c|c|c|c|}
\hline \multirow{2}{*}{ Regression Coefficients } & \multicolumn{2}{|c|}{ Effectiveness } & \multicolumn{2}{|c|}{ Convenience } & \multicolumn{2}{|c|}{ Global Satisfaction } \\
\hline & Model 1 & Model 2 & Model 1 & Model 2 & Model 1 & Model 2 \\
\hline Constant & 75.97 & 69.57 & 57.98 & 57.99 & 63.57 & 63.70 \\
\hline MDI use & $3.26(.10)$ & $2.85(.21)$ & $3.16(.10)$ & $3.11(.16)$ & $2.13(.34)$ & $1.69(.51)$ \\
\hline Well-controlled asthma & $9.15(<(.001)$ & $8.03(.038)$ & $4.14(.051)$ & $4.02(.28)$ & $11.82(<0.001)$ & $10.60(.02)$ \\
\hline MAQ score & $0.44(.58)$ & $0.44(.59)$ & $1.90(.02)$ & $1.90(.02)$ & $1.84(.042)$ & $1.84(.043)$ \\
\hline$\%$ Predicted $\mathrm{FEV}_{1}$ & $-0.05(.25)$ & $-0.05(.26)$ & $0.06(.12)$ & $0.06(.12)$ & $-0.03(.45)$ & $-0.03(.47)$ \\
\hline $\mathrm{F}_{\mathrm{ENO}}(\mathrm{ppm})$ & $-0.06(.33)$ & $-0.06(.33)$ & $-0.00(.95)$ & $-0.00(.95)$ & $0.03(.68)$ & $0.03(.68)$ \\
\hline MDI use $\times$ well-controlled asthma & & $1.60(.73)$ & & $0.18(.97)$ & & $1.76(.73)$ \\
\hline $\mathrm{R}^{2}$ & 0.14 & 0.14 & 0.11 & 0.11 & 0.16 & 0.16 \\
\hline $\begin{array}{l}\text { Figures in parentheses are significance values fo } \\
\text { TSQM = Treatment Satisfaction Questionnaire } \\
\text { MDI = metered-dose inhaler } \\
\text { MAQ = Medication Adherence Questionnaire } \\
\text { F }_{\mathrm{ENO} \text { = fraction of expired nitric oxide }} \\
\mathrm{ppm}=\text { parts per million }\end{array}$ & $\begin{array}{l}\text { gression coefficients. A } \\
\text { Medication }\end{array}$ & els are based on & m 100 subjects $\mathrm{e}$ & $\mathrm{g}$ an $\mathrm{MDI}$ or & & \\
\hline
\end{tabular}

portion of the variability in the model, and it is likely that other factors that are not evaluated in this study are more important determinants of patient satisfaction.

Most subjects in our study had well-controlled airway inflammation, as evidenced by $\mathrm{F}_{\mathrm{ENO}}$ levels (Table 2). Pulmonary function was, however, better in the MDI users. This discrepancy between $\mathrm{F}_{\mathrm{ENO}}$ and clinical parameters (asthma control and spirometry) is not entirely surprising, as $\mathrm{F}_{\mathrm{ENO}}$ may be useful only as a complementary marker to other asthma assessment tools. ${ }^{21}$ Previous investigators have also reported poor correlation between $\mathrm{F}_{\mathrm{ENO}}$ levels and other clinical markers of asthma. ${ }^{22,23}$

More importantly, we found that subjects using MDIs reported better TSQM domain scores for Effectiveness, Convenience, and Global Satisfaction. This may partly be linked to our observation that MDI users had better-controlled disease (Table 2). Subjects using MDIs also showed greater overall adherence to treatment, and this is likely a result of greater treatment satisfaction among MDI users. However, after adjusting for treatment adherence, lung function, airway inflammation, and overall asthma control,
MDI use did not significantly influence TSQM domain scores (Table 5). Both DPIs and MDIs provide equivalent clinical effect when taken appropriately and thus may provide equivalent patient satisfaction with long-term use. We also demonstrated a significant positive correlation between MAQ score and the Global Satisfaction and Convenience domain scores of the TSQM (Table 3). This association between medication adherence and treatment satisfaction has been previously noted for several chronic medical conditions. ${ }^{24}$

Our study has certain limitations. All subjects using DPIs were inhaling their medications through single-capsule devices. This might limit the generalizability of our data because multi-dose devices are commonly used in other settings. Although all subjects had been previously trained to use their inhaler devices properly, we did not specifically verify the correctness of inhaler technique at the time of evaluation in this study. We also used a generic instrument to assess satisfaction with inhaled therapy, as some of the more inhaler-specific questionnaires used in other clinical trials were not available in our local language. 


\section{Patient Satisfaction With Inhalers}

We conclude that MDIs are associated with better disease control and treatment adherence among subjects with asthma. Even though the subjects using MDIs derived greater treatment satisfaction than those using commonly available DPIs in India, after adjusting for other clinical variables, both devices seemed to provide equivalent treatment satisfaction.

\section{ACKNOWLEDGMENT}

The authors are grateful to Quintiles for granting permission to use the Treatment Satisfaction Questionnaire for Medication (TSQM) in this study and for providing a translation.

\section{REFERENCES}

1. Dolovich MB, Ahrens RC, Hess DR, Anderson P, Dhand R, Rau JL, et al. Device selection and outcomes of aerosol therapy: evidence-based guidelines: American College of Chest Physicians/American College of Asthma, Allergy, and Immunology. Chest 2005;127(1):335-371.

2. Small M, Anderson P, Vickers A, Kay S, Fermer S. Importance of inhaler-device satisfaction in asthma treatment: real-world observations of physician-observed compliance and clinical/patient-reported outcomes. Adv Ther 2011;28(3):202-212.

3. Price D, Harrow B, Small M, Pike J, Higgins V. Establishing the relationship of inhaler satisfaction, treatment adherence, and patient outcomes: a prospective, real-world, cross-sectional survey of US adult asthma patients and physicians. World Allergy Organ J 2015;8(1):26.

4. Rajan SK, Gogtay JA. Ease-of-use, preference, confidence, and satisfaction with Revolizer((R)), a novel dry powder inhaler, in an Indian population. Lung India 2014;31(4):366-374.

5. Global Initiative for Asthma. 2017 Global Strategy for Asthma Management and Prevention. http://ginasthma.org/2017-gina-reportglobal-strategy-for-asthma-management-and-prevention/ Accessed February 20, 2018

6. Miller MR, Hankinson J, Brusasco V, Burgos F, Casaburi R, Coates A, et al. Standardisation of spirometry. Eur Respir J 2005;26(2):319-338.

7. Aggarwal AN, Gupta D, Jindal SK. Development of a simple computer program for spirometry interpretation. J Assoc Physicians India 2002;50:567-570

8. ATS/ERS recommendations for standardized procedures for the online and offline measurement of exhaled lower respiratory nitric oxide and nasal nitric oxide, 2005. Am J Respir Crit Care Med 2005;171(8):912-930.

9. Atkinson MJ, Sinha A, Hass SL, Colman SS, Kumar RN, Brod M, et al. Validation of a general measure of treatment satisfaction, the Treatment Satisfaction Questionnaire for Medication (TSQM), using a national panel study of chronic disease. Health Qual Life Outcomes 2004;2:12.

10. Regnault A, Balp MM, Kulich K, Viala-Danten M. Validation of the Treatment Satisfaction Questionnaire for Medication in patients with cystic fibrosis. J Cyst Fibros 2012;11(6):494-501.

11. Chen H, Rosenzweig EB, Gotzkowsky SK, Arneson C, Nelsen AC, Bourge RC. Treatment satisfaction is associated with improved qual- ity of life in patients treated with inhaled treprostinil for pulmonary arterial hypertension. Health Qual Life Outcomes 2013;11:31.

12. Morisky DE, Green LW, Levine DM. Concurrent and predictive validity of a self-reported measure of medication adherence. Med Care 1986;24(1):67-74

13. Shikiar R, Rentz AM. Satisfaction with medication: an overview of conceptual, methodologic, and regulatory issues. Value Health 2004; 7(2):204-215

14. Chervinsky P, Baker J, Bensch G, Parasuraman B, Boggs R, Martin $\mathrm{P}$, et al. Patient-reported outcomes in adults with moderate to severe asthma after use of budesonide and formoterol administered via 1 pressurized metered-dose inhaler. Ann Allergy Asthma Immunol 2008;101(5):463-473.

15. Weiss KB, Paramore LC, Liljas B, Revicki DA, Luce BR. Patient satisfaction with budesonide Turbuhaler versus triamcinolone acetonide administered via pressurized metered-dose inhaler in a managed care setting. J Asthma 2005;42(9):769-776.

16. Ferguson GT, Ghafouri M, Dai L, Dunn LJ. COPD patient satisfaction with ipratropium bromide/albuterol delivered via Respimat: a randomized, controlled study. Int J Chron Obstruct Pulmon Dis 2013; 8:139-150.

17. Miravitlles M, Montero-Caballero J, Richard F, Santos S, GarciaRivero JL, Ortega F, et al. A cross-sectional study to assess inhalation device handling and patient satisfaction in COPD. Int J Chron Obstruct Pulmon Dis 2016;11:407-415.

18. O'Connor RD, Patrick DL, Parasuraman B, Martin P, Goldman M. Comparison of patient-reported outcomes during treatment with adjustable- and fixed-dose budesonide/formoterol pressurized metereddose inhaler versus fixed-dose fluticasone propionate/salmeterol dry powder inhaler in patients with asthma. J Asthma 2010;47(2):217223.

19. Pascual S, Feimer J, De Soyza A, Sauleda Roig J, Haughney J, Padulles L, et al. Preference, satisfaction and critical errors with Genuair and Breezhaler inhalers in patients with COPD: a randomised, cross-over, multicentre study. NPJ Prim Care Respir Med 2015;25: 15018.

20. van der Palen J, Ginko T, Kroker A, van der Valk P, Goosens M, Padulles L, et al. Preference, satisfaction and errors with two dry powder inhalers in patients with COPD. Expert Opin Drug Deliv 2013;10(8):1023-1031.

21. Dweik RA, Boggs PB, Erzurum SC, Irvin CG, Leigh MW, Lundberg JO, et al. An official ATS clinical practice guideline: interpretation of exhaled nitric oxide levels (FENO) for clinical applications. Am J Respir Crit Care Med 2011;184(5):602-615.

22. Khalili B, Boggs PB, Shi R, Bahna SL. Discrepancy between clinical asthma control assessment tools and fractional exhaled nitric oxide. Ann Allergy Asthma Immunol 2008;101(2):124-129.

23. Vijverberg SJ, Koster ES, Koenderman L, Arets HG, van der Ent CK, Postma DS, et al. Exhaled NO is a poor marker of asthma control in children with a reported use of asthma medication: a pharmacy-based study. Pediatr Allergy Immunol 2012;23(6):529-536.

24. Barbosa CD, Balp MM, Kulich K, Germain N, Rofail D. A literature review to explore the link between treatment satisfaction and adherence, compliance, and persistence. Patient Prefer Adherence 2012;6:39-48.

This article is approved for Continuing Respiratory Care Education credit. For information and to obtain your CRCE

(free to AARC members) visit

www.rcjournal.com

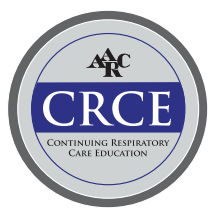

